\title{
Serological evidence of canine exposure to arthropod-borne pathogens in different landscapes in Rio de Janeiro, Brazil
}

\author{
Liliane Maria Valentim Willi a,*, Flavya Mendes-de-Almeida a , Celeste da Silva Freitas de Souza ${ }^{\text {b }}$, Tainá Laeta ${ }^{c}$, \\ Jonimar Pereira Paiva ${ }^{\mathrm{d}}$, Marcia Gonçalves Nobre de Miranda ${ }^{\mathrm{e}}$, Fabiana Batalha Knackfuss ${ }^{\mathrm{f}}$, Norma Labarthe ${ }^{\mathrm{a}, \mathrm{g}}$ \\ a Universidade Federal Fluminense, Faculdade de Veterinária, Rua Vital Brazil Filho 64, 24230340 Niterói, RJ, Brazil \\ b Laboratório de Imunomodulação e Protozoologia, Instituto Oswaldo Cruz, Fiocuz, Av. Brasil 4365, 21040360 Rio de Janeiro, RJ, Brazil \\ c Programa de Pós-Graduação em Geografia, Departamento de Geografia, Instituto de Geociências, Universidade Federal do Rio de Janeiro, 21941972 Rio de Janeiro, RJ, Brazil \\ ' Departamento de Medicina e Cirurgia Veterinária, Instituto de Veterinária, Universidade Federal Rural do Rio de Janeiro, 23890000 Seropédica, RJ, Brazil \\ e Médica Veterinária, Vet Ypiranga, 22231120 Rio de Janeiro, RJ, Brazil \\ ${ }^{\mathrm{f}}$ Escola de Ciências da Saúde, Universidade do Grande Rio, 25071202 Duque de Caxias, RJ, Brazil \\ ${ }^{g}$ Fundação Oswaldo Cruz, Av. Brasil 4365, 21040360 Rio de Janeiro, RJ, Brazil
}

\section{A R T I C L E I N F O}

\section{Article history:}

Received 18 March 2016

Received in revised form 25 November 2016

Accepted 28 November 2016

Available online 5 December 2016

\section{Keywords:}

Anaplasma

Ehrlichia

Heartworm

Leishmania

Canine parasites

\begin{abstract}
A B S T R A C T
Arthropod-borne infections are dependent on environmental conditions, and several combinations of natural and human-related variables play an important role in vector populations as well as the life cycle of agents carried by the arthropods. The top 5 canine arthropod-transmitted agents, Dirofilaria immitis, Leishmania spp., Ehrlichia canis, Anaplasma phagocytophilum, and Borrelia burgdorferi infect unprotected animals without propensity. The purpose of this study was to determine the prevalence of these parasite species in three different landscape settings (sandbanks, plains and mountains) along a 60-km line. During a 6-month period, blood samples were collected from dogs (>12 months old) living in the different settings. Prevalence of $D$. immitis was determined by modified Knott test and ELISA. Prevalence of E. canis, A. phagocytophilum, and B. burgdorferi was determined by ELISA, and Leishmania spp. by ELISA, indirect immunofluorescence, and immunocromatographic assays. D. immitis was most prevalent in the sandbank (68.9\%) as well as Leishmania spp. (34.5\%), and tick-transmitted agents, A. phagocytophilum and E. canis in the plains (61.7\%). B. burgdorferi was not detected. Depending on the resources for arthropods present in regions, dogs are likely to be exposed to different arthropod-borne parasites and should receive preventives tailored to the risk of infection in the region in which the dog resides.
\end{abstract}

(C) 2016 Elsevier B.V. All rights reserved.

\section{Introduction}

Dirofilaria immitis, Ehrlichia canis, Anaplasma phagocytophilum, Borrelia burgdorferi and Leishmania spp., are important arthropodtransmitted pathogens of medical and veterinary concern (Labarthe et al., 2003; Dantas-Torres, 2008; Bowman et al., 2009; Villeneuve et al., 2011; Cardoso et al., 2012). It is known that D. immitis is one of the most important nematodes in veterinary medicine due to the high numbers of infected domestic and wild animals (Labarthe et al., 2002; AHS, 2014). This parasite is vectored by several culicidae species that may present hemi-synanthropic (e.g., Ochlerotatus scapularis and Aedes taeniorhynchus) or synanthropic (e.g. Culex quinquefasciatus) behavior (Labarthe et al., 1998). Tick-borne pathogens such as E. canis, A. phagocytophilum, and B. burgdorferi are the cause of important diseases for humans and domestic or wild animals (Little et al., 2014;

\footnotetext{
* Corresponding author.

E-mail address: liliwillimonteiro@hotmail.com (L.M.V. Willi).
}

Sykes, 2014). Rhipicephalus sanguineus, known as the brown dog tick, is their principal vector species in Brazil (Labruna and Pereira, 2001).

Similarly, Leishmania spp. have been included in the list of the top 5 parasites that affect an incalculable number of domestic, synanthropic, or wild animals, and is considered one of the most prevalent neglected human infections. It is believed that approximately 200,000 to 400,000 new cases of human visceral leishmaniasis occur annually, with $>90 \%$ of these cases occurring in 6 developing countries, including Brazil (WHO, 2015). From 0.7 to 1.3 million new cases of cutaneous leishmaniasis are reported annually, with approximately $95 \%$ of cases occurring in the Americas, the Mediterranean basin, the Middle East, and Central Asia. In Brazil, both cutaneous (caused by Leishmania braziliensis) and visceral forms are endemic (Aguilar et al., 1987), and outbreaks are usually related to disorderly land occupation (Kawa and Sabroza, 2002; Aguiar et al., 2014).

The occurrence of infected dogs with $D$. immitis or tick-borne parasites is high in tropical and subtropical areas and vectors are prevalent throughout the year in those areas (Labarthe et al., 1997; Labarthe et al., 2002; Genchi et al., 2009; Willi et al., 2012; Little et al., 2014). In 
Brazil D. immitis infections are known to be frequent in coastal areas where nature is better conserved, providing better conditions for development of culicidae (Labarthe et al., 2014). Similarly, as with the other vector-borne pathogens, the distribution of Leishmania spp. depends on vector populations, and therefore, the expansion of phlebotomies sand flies habitats is directly related to the distribution of leishmaniasis (Killick-Kendrick, 1999; Maia-Elkhoury et al., 2008). Undoubtedly, the environment plays an important role in the occurrence of vectorborne pathogens, since it is strictly related to the development of their vectors. Therefore, the present study assessed the prevalence of D. immitis, E. canis, A. phagocytophilum, B. burgdorferi and Leishmania spp. in dogs living in different landscape settings in a Brazilian tropical area.

\section{Materials and methods}

\subsection{Ethical aspect and study area}

This study was approved by the Comissão de Ética no Uso de Animais - CEUA of the Fundação Oswaldo Cruz (protocol number: LW-33/11). This study was conducted from August 2011 to January 2012 in 3 different landscape areas of the state of Rio de Janeiro ( $\left.22^{\circ} 54^{\prime} \mathrm{S} 43^{\circ} 10^{\prime} \mathrm{W}\right)$, Brazil. The landscapes were located along a $60-\mathrm{km}$ line from a sandbank section to the mountain region in the eastern area of the state of Rio de Janeiro.

In the sandbank area (sea level) (Site 1), one locale was between the lagoon and the seashore and the other at the opposite margin of the lagoon. In the plains (50 $\mathrm{m}$ above sea level) (Site 2), the area studied was between the sandbank and the mountain regions. Finally, in the mountain landscape, 2 locales were included, one at $140 \mathrm{~m}$ and the other at $840 \mathrm{~m}$ above sea level (Site 3) (Fig. 1). The main features considered for all 3 landscapes were distance from the coast, land use, altitude, human population density, and environmental conservation status. The landscape margins and surface features were determined by visual analysis using Google Earth. Locations where dogs were sampled were acquired by accessing the American global navigation satellite system (GNSS) using a global position system receiver (GPSMAP 62 receiver, GARMIN). Acquired locations were subsequently processed in ArcGIS 10 software.

In the sandbank area, human population density was intermediate and conserved areas were scarce. The locale between the lagoon and the seashore consists basically of homes that are devoid of public water supply, sewage treatment, and paved streets, although public power had recently been installed. The houses had an unfinished aspect, with filthy yards and no trees. At the opposite margin of the sandbank region, houses were brick and well-finished. Roads were partially paved, and public power, water supplies, and public sewage treatment were the norm.

In the plains, the human occupation was dense, leading to intense destruction of natural resources in the region. The population in the area was expanding as people were abandoning urban settings and moving to these more rural areas. Streets were generally unpaved and houses were unfinished; however, public power and water supplies were available, but there was no public sewage treatment.

In the mountain landscape, the balance of nature was conserved, and human density was the lowest of the 3 regions. The 140 -m point was set in a small village surrounded by Atlantic forest and some rural properties, where only the principal streets were paved, public power and water supplies were present, but sewage treatment was not. The 840$\mathrm{m}$ point was a rural village with unpaved streets, water supply from local sources, and poor public power supply, situated in Atlantic forest.

\subsection{Animals and blood sampling}

Dogs ( $\mathrm{n}=333$ ) estimated to be at least one year of age were used in this study. The study aimed to evaluate as many dogs as possible in a given area. To be included in the research, dogs had to have lived within the study area for at least 6 months and owners had to complete an Informed Consent Form giving permission for the dog's participation in the study. Whole blood samples were collected from each dog through the puncture of the cephalic vein and stored in sterile plastic tubes containing anticoagulant (EDTA). Afterwards, each sample was divided in an aliquot of whole blood and from the other was obtained the plasma.

\subsection{Laboratorial procedures}

Whole blood samples were used to detect the presence of microfilariae by using a modified Knott test (Newton and Wright, 1956). In addition, plasma samples were tested for the presence of D. immitis, E. canis, A. phagocytophilum, and B. burgdorferi antigen using a commercial ELISA test (SNAP 4Dx®, IDEXX Laboratories, Maine, USA) following the manufacturer's instructions. Dogs were considered infected with $D$. immitis when microfilariae or antigens were detected and with E. canis, A. phagocytophilum, or B. Burgdorferi when antibodies were detected.

The detection of Leishmania spp. infection was performed by the ELISA (EIE Leishmaniose Canina - BioManguinhos/Fiocruz, Rio de Janeiro, Brazil) and immunofluorescence antibody test (IFAT) (Leishmaniose Canina - BioManguinhos/Fiocruz, Rio de Janeiro, Brazil). In addition, an immunocromatographic assay (TR DPP® canine visceral leishmaniasis BioManguinhos/Fiocruz, Rio de Janeiro, Brazil) was performed. Dogs were considered positive for cutaneous leishmaniasis by ELISA and IFAT and for visceral leishmaniasis when tested positive by ELISA, IFAT and TR DPP.

\subsection{Data analysis}

Data were entered into EPI INFO 2000 data forms generated for this study, and data entry was verified for accuracy by 2 researchers. Nonparametric analysis was performed by chi square or Fisher's exact tests.

\section{Results}

After receiving owners' consent, dogs were tested for $D$. immitis infection and tick-borne parasite seroprevalence; however, only $56.7 \%$ (189/333) could be tested for seroprevalence to Leishmania spp. because the ethical permission limited the volume of blood that could be collected. Therefore, only surpluses could be used.

The overall prevalence of the pathogens studied was 37\% (123/333) for $D$. immitis infection; $46.8 \%$ (156/333) for tick-borne parasite seroprevalence and 27\% (51/189) for Leishmania spp. seroprevalence. It is important to note that $B$. burgdorferi was not detected in the dogs tested (Table 1).

In the sandbank area, the most prevalent parasite was $D$. immitis $(68.9 \% ; 115 / 167)$ when compared with tick-borne parasites $(43.7 \%$; $\left.73 / 167 ; x^{2}=21.465 ; \mathrm{df}=1 ; P<0.0001\right)$ or Leishmania spp. (34.5\%; $39 / 113 ; x^{2}=32.128 ; \mathrm{df}=1 ; P<0.0001$ ). There was no difference in the seroprevalence between tick-borne pathogens and Leishmania spp. $\left(x^{2}=2.376 ; \mathrm{df}=1 ; P=0.1564\right)$ (Table 1$)$.

In the plains, tick-borne pathogens had a significantly higher prevalence $(61.7 \% ; 37 / 60)$ compared with $D$. immitis infection $\left(0 / 60 ; x^{2}=\right.$ 53.494; df $=1 ; P<0.0001)$ or Leishmania spp. $\left(22.2 \% ; 10 / 45 ; x^{2}=\right.$ $16.181 ; \mathrm{df}=1 ; P=0.0001)$. In this landscape a significant difference between $D$. immitis infection and Leishmania spp. seroprevalence was observed ( $x^{2}=14.737 ; \mathrm{df}=1 ; P=0.0005$ ) (Table 1 ).

In the mountain area, the seroprevalence of tick-borne pathogens was highest $(43.4 \%$; 46/106) compared with the prevalence of D. immitis infection $\left(7.5 \% ; 8 / 106 ; x^{2}=35.880 ; \mathrm{df}=1 ; P<0.0001\right)$ or Leishmania spp. $\left(6.4 \% ; 2 / 331 ; x^{2}=14.383\right.$; $\left.\mathrm{df}=1 ; P=0.0003\right)$. No difference in $D$. immitis infection and Leishmania spp. was detected $\left(x^{2}=\right.$ 14.383; $\mathrm{df}=1 ; P=0.8523$ ) (Table 1 ). 

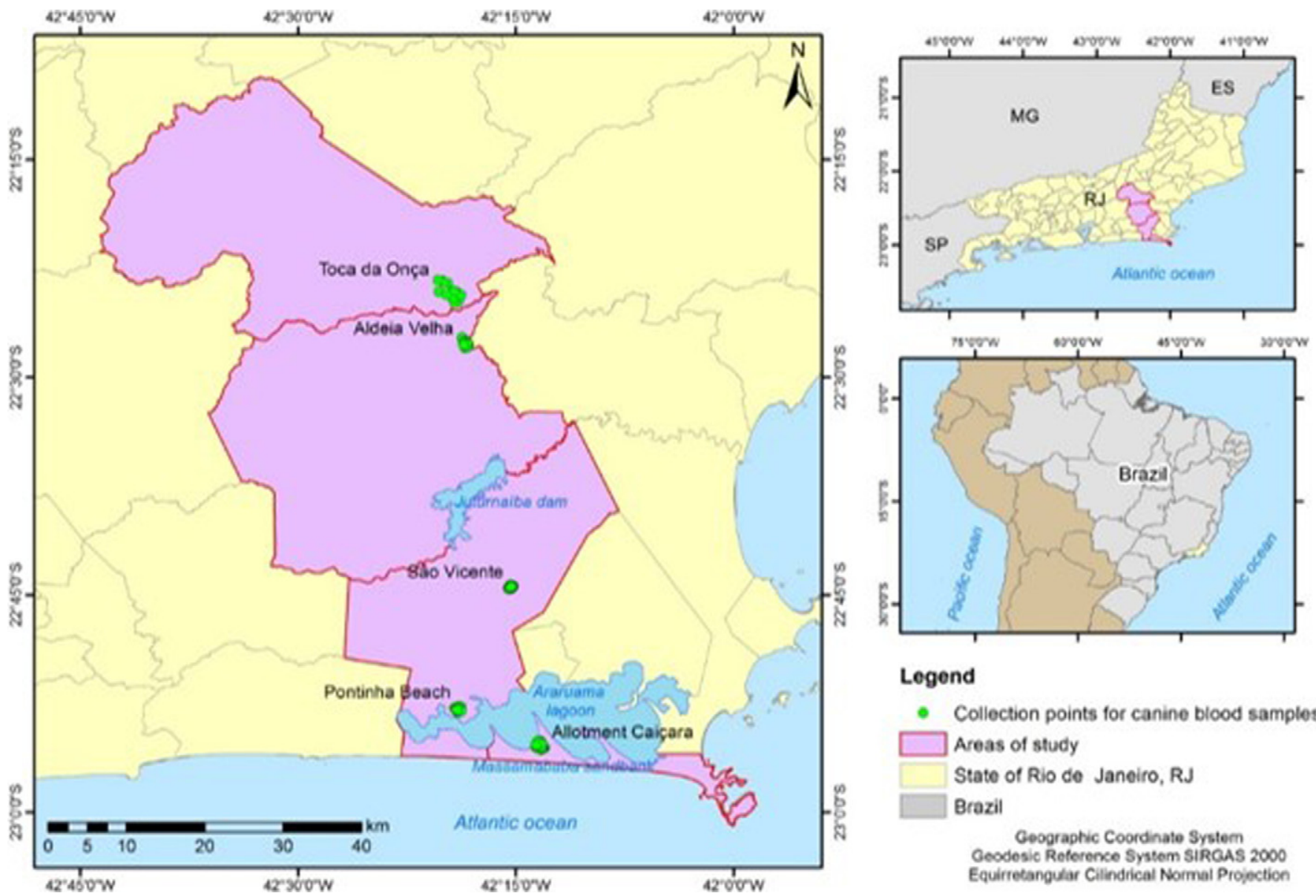

- Collection points for canine blood samples

Areas of study

State of Rio de Janeiro, RJ

Brazil

\section{Geographic Coordinate System}

Ceodesio Reference System SiRGas 2000 Equirretangular Cilindrical Normal Projection

Fig. 1. Locations of the landscapes were studied in the eastern state of Rio de Janeiro, Brazil.

Of 123 dogs positive for $D$. immitis infection, 93.5\% (115/123) were diagnosed at the sandbank. Likewise, of all 51 dogs diagnosed with Leishmania spp., 76.5\% (39/51) were from the sandbank region (Table 1). Of the 115 dogs positive for $D$. immitis in the sandbank area, 39 also were co-infected with $E$. canis and 15 with $E$. canis and A. phagocytophilum. Finally, in the mountain region, 4 of the 8 dogs infected with $D$. immitis were co-infected with $E$. canis and A. phagocytophilum.

\section{Discussion}

Landscape characteristics are of paramount importance for arthropod populations and different arthropod communities can be highly affected by slight environmental changes. Considering those concepts, it is interesting to note that according to the detection of mosquitoborne infections and antibodies of tick-borne pathogens, ticks and

Table 1

Seroprevalence of Dirofilaria immitis, tick-borne diseases and Leishmania spp. in dogs from different landscapes in Brazil.

\begin{tabular}{|c|c|c|c|c|}
\hline \multirow[b]{2}{*}{ Parasite } & \multicolumn{4}{|c|}{ No. positive/total (\%) } \\
\hline & Sandbank & Plains & Mountain & Overall \\
\hline $\begin{array}{l}\text { Mosquito-borne* } \\
\text { Dirofilaria immitis }\end{array}$ & $115 / 167(68.9)^{\mathrm{a} \dagger}$ & $0 / 60^{\mathrm{b} \dagger}$ & $8 / 106(7.5)^{\mathrm{b} \dagger}$ & $123 / 333(37.0)$ \\
\hline $\begin{array}{l}\text { Tick-borne** } \\
\text { Ehrlichia canis } \\
\text { E. canis }+ \text { Anaplasma phagocytophilum } \\
\text { A. phagocytophilum } \\
\text { Combined }\end{array}$ & $\begin{array}{l}51 / 167(30.5) \\
22 / 167(41.7) \\
0 / 167 \\
73 / 167(43.7)^{a \dagger \dagger}\end{array}$ & $\begin{array}{l}25 / 60(41.7) \\
12 / 60(20.0) \\
0 / 60 \\
37 / 60(61.7)^{\mathrm{b}+t}\end{array}$ & $\begin{array}{l}30 / 106(28.3) \\
14 / 106(13.2) \\
2 / 106(1.9) \\
46 / 106(43.4)^{\mathrm{a}+\dagger}\end{array}$ & $\begin{array}{l}106 / 333(31.8) \\
48 / 333(14.4) \\
2 / 333(0.6) \\
156 / 333(46.8)\end{array}$ \\
\hline $\begin{array}{l}\text { Sandfly-borne } \\
\text { Leishmania braziliensis } \\
\text { Leishmania infantum } \\
\text { Combined }\end{array}$ & $\begin{array}{l}38 / 113(33.6) \\
1 / 113(0.9) \\
39 / 113(34.5)^{a \dagger}\end{array}$ & $\begin{array}{l}9 / 45(20.0) \\
1 / 45(2.2) \\
10 / 45(22.2)^{a, b+t \dagger}\end{array}$ & $\begin{array}{l}2 / 31(6.4) \\
0 / 31 \\
2 / 31(6.4)^{b \dagger}\end{array}$ & $\begin{array}{l}49 / 189(25.9) \\
2 / 189(1.1) \\
51 / 189(27.0)\end{array}$ \\
\hline
\end{tabular}

Different letters within rows indicate significant difference $(P<0.001)$. Different symbols within columns indicate significant difference $(P<0.001)$.

* Tested by modified Knott test and ELISA commercial test (SNAP 4Dx®, IDEXX Laboratories, Maine, USA).

** Tested by ELISA commercial test (SNAP 4Dx®).

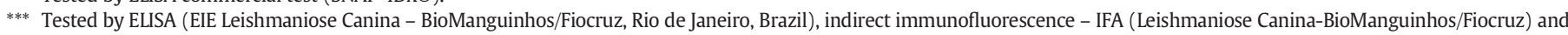
immunocromatographic assay (TR DPP® canine visceral leishmaniasis - BioManguinhos/Fiocruz). 
mosquitoes seemed to share the same habitats. These results suggest that within a landscape there are different habitats, which provide environmental conditions for development of the vector. Mosquitoes are water-borne and need warm temperatures and humidity, while Lutzomyia spp. need organic matter substratum in places with shade and cool temperatures. Results of the present study indicate that tickborne diseases, and hence tick vectors, are most frequently found in the dry, warm and heavily populated suburban areas with substandard housing and squalor (Labarthe et al., 1998; Killick-Kendrick, 1999; Labruna and Pereira, 2001).

Dirofilaria immitis infection was higher in the coastal environment, as it has been previously observed in other Brazilian regions (Labarthe et al., 2014). The coastal environment provides richness of salinity that favors populations of the competent vector Aedes taeniorhynchus (Labarthe et al., 1998). However, results from the plains may be somewhat unexpected since the prevalence of $D$. immitis infections declined in dogs further from the coast. The squalor and the degradation of natural resources of the plains could be the main reason for decline in the establishment of hemi-synanthropic mosquito populations, resulting in the absence of infection in the landscape. However, the well-conserved Atlantic forest resources of the mountains provided sufficient mosquito vectors to transmit $D$. immitis to the dogs, although at low rates, as has been observed previously (Labarthe et al., 2014). The source of infection to the mosquitoes and from the mosquitoes to the canine population of the mountains is unknown. However, microfilaremic dogs travelling with their owners or sylvatic microfilaremic Mustelidae or Canidae cannot be disregarded as a source of infective microfilariae (Bowman et al., 2009; Brown et al., 2012).

Anaplasma phagocytophilum is rarely reported in dogs in Brazil. This infection is vectored by Ixodes spp. ticks, which are rarely found on dogs in Brazil. Anti-A. phagocytophilum antibodies were frequently detected in association with anti-E. canis antibodies in this study, suggesting that both parasites are transmitted by the same tick species. However, it is also possible that cross-reaction among different Anaplasma species may have occurred (Santos et al., 2011). The only landscape where dogs harbored anti-A. phagocytophilum antibodies and no anti-E. canis antibodies was in the mountains, where Amblyomma cajennense, the wood tick, occurs frequently and has been suggested as a vector for the bacteria. Therefore, it is possible that dogs that were allowed to roam free by the owners invade the natural environment and become infected (Labruna and Pereira, 2001; Onofrio et al., 2009; Santos et al., 2011).

The highest seroprevalence of $E$. canis was observed in the plains where substandard houses probably provide niches for its principal vector, $R$. sanguineus. Although the rubbish found in the plains areas certainly contributed to enhance Anaplasmataceae transmission, the well-conserved environment of the mountains or the sandbank also provided sufficient resources for $R$. sanguineus populations (Aguiar et al., 2007), and the seroprevalence of $E$. canis was relatively high in both of those regions.

Detection of anti-Leishmania antibodies in canine blood samples was not surprising, and the integumentary form is endemic in Rio de Janeiro, especially where substandard land occupation has occurred (Kawa and Sabroza, 2002; Aguiar et al., 2014). The detection of low antibody levels to Leishmania in the canine blood samples (ELISA and IFA tests) were mainly from the 2 less-conserved study areas (sandbank and plains), suggesting that $L$. braziliensis is a frequent parasite at those sites, and further confirming previous reports of how land occupation influences Leishmania spp. prevalence and distribution. Furthermore, the presence of 2 dogs infected with $L$. infantum (positive by ELISA, IFA and TR DPP ${ }^{\circledR}$ tests) in the crude occupied lowland areas provided evidence of the presence of the vector Lutzomyia longipalpis (Brazil et al., 1989, 2012). The confirmed autochthonous infection nearby (Paula et al., 2009) provides additional evidence of the ongoing risk for infection with this lifethreatening zoonotic parasite.

The present study provides evidence that the lack of basic sanitation of homes and the neglected conditions in the nearby natural environment play an important role in the provision of resources for arthropod-borne canine infections. Furthermore, dogs in the eastern state of Rio de Janeiro were shown to be at risk of becoming infected by preventable lifethreatening parasites with zoonotic potential. These data also provide evidence that enable veterinarians to advise their clients to use appropriate and effective preventive parasite control treatments for their pets, especially when they travel to high-risk areas and to routinely screen their patients for parasites. Further studies must be conducted to better understand the relationship among the environment, vectors, parasites and hosts.

\section{Ethical standards}

All of the studies reported herein were performed in compliance with current applicable local laws and regulations.

\section{Conflict of interest}

Liliane Willi Monteiro, Celeste Freitas de Souza, Tainá Laeta, Marcia Nobre de Miranda and Fabiana Batalha Knackfuss have no competing interests. Flavya-Mendes-de-Almeida is a consultant for Idexx Laboratories. Jonimar Paiva is a consultant for Zoetis in Brazil. Norma Labarthe is a consultant for Bayer Animal Health, Idexx Laboratories, and Zoetis in Brazil.

\section{Acknowledgements}

The authors acknowledge Marcia Chame for the contribution to study design and Carolina Haje, Daniel Marques, Daniel Paiva, Daniel Ribeiro, Marcela Machado, Monique Paiva and Thiago Gomes for assistance in the acquisition of data. The authors thank Kathleen Newcomb, Nathalie, VA, USA for editorial assistance in the preparation of this manuscript. The authors are grateful to the owners and the dogs of the study. The authors also acknowledge Bayer S.A. and Linavet for providing part of the kits.

\section{References}

Aguiar, D.M., Cavalcante, G.T., Pinter, A., Gennari, S.M., Camargo, L.M., Labruna, M.B., 2007. Prevalence of Ehrlichia canis (Rickettsiales: Anaplasmataceae) in dogs and Rhipicephalus sanguineus (Acari: Ixodidae) ticks from Brazil. J. Med. Entomol. 44 (1), 126-132.

Aguiar, G.M., Azevedo, A.C.R., Medeiros, W.M., Alves, J.R.C., Rendeiro, V., 2014. Aspects of ecology of phlebotomines (Diptera: Psychodidae: Phlebotominae) in an area of cutaneous leishmaniasis occurrence, municipality of Angra does Reis, coast of Rio de Janeiro State, Brazil. Rev. Inst. Med. Trop. 56, 143-149.

Aguilar, C.M., Rangel, E.F., Grimaldi Filho, G., Momem, H., 1987. Human, canine and equine leishmaniasis caused by Leishmania braziliensis in an endemic area in the State of Rio de Janeiro. Mem. Inst. Oswaldo Cruz 82 (1), 143.

Bowman, D., Little, S.E., Lorentzen, L., Shields, J., Sullivan, M.P., Carlin, E.P., 2009. Prevalence and geographic distribution of Dirofilaria immitis, Borrelia burgdorferi, Ehrlichia canis, and Anaplasma phagocytophilum in dogs in the United States: results of a national clinic-based serologic survey. Vet. Parasitol. 160 (1-2), 138-148.

Brazil, R.P., Brazil, B.G., Gouvea, M.C., Almeida, D.C., Oliveira, S.M.P., Menezes, J.A., 1989. Epidemiological studies on cutaneous leishmaniasis in the State of Rio de Janeiro, Brazil. In: Hart, D.T. (Ed.), Leishmaniasis. The Current Status and New Strategies for Control. Plenum Press, London, pp. 59-62.

Brazil, R.P., Pontes, M.C., Passos, W.L., Fuzari, A.A., Brazil, B.G., 2012. Lutzomyia longipalpis (Diptera: Psychodidae: Phlebotominae) in the region of Saquarema: potential area of visceral leishmaniasis transmission in the state of Rio de Janeiro, Brazil. Rev. Soc. Bras. Med. Trop. 45 (1), 120-121

Brown, H.E., Harrington, L.C., Kaufman, P.E., McKay, T., Bowman, D.D., Nelson, C.T., Wang, D., Lund, R., 2012. Key factors influencing canine heartworm, Dirofilaria immitis, in the United States. Parasit. Vectors 5, 245

Cardoso, L., Mendao, C., Madeira de Carvalho, L., 2012. Prevalence of Dirofilaria immitis, Ehrlichia canis, Borrelia burgdorferi sensu lato, Anaplasma spp. and Leishmania infantum in apparently healthy and CVBD-suspect dogs in Portugal-a national serological study. Parasit. Vectors 5, 62.

Current Canine Guidelines for the Prevention, Diagnosis, and Management of Heartworm (Dirofilaria immitis) Infection in Dogs. American Heartworm Society, 2014. (Accessed 2015 March 10) Available at: http://www.americanheartwormsociety.org/

Dantas-Torres, F., 2008. Canine vector-borne diseases in Brazil. Parasit. Vectors 1, 25

Genchi, C., Rinaldi, L., Mortarino, M., Genchi, M., Cringoli, G., 2009. Climate and Dirofilaria infection in Europe. Vet. Parasitol. 163 (4), 286-292. 
Kawa, H., Sabroza, P.C., 2002. Spatial distribution of tegumentary leishmaniasis in the city of Rio de Janeiro. Cad. Saude Publica 18 (3), 853-865.

Killick-Kendrick, R., 1999. The biology and control of phlebotomine sand flies. Clin. Dermatol. 17 (3), 279-289.

Labarthe, N., Almosny, N., Guerrero, J., Duque-Araujo, A.M., 1997. Description of the occurrence of canine dirofilariasis in the State of Rio de Janeiro, Brazil. Mem. Inst. Oswaldo Cruz 92 (1), 47-51.

Labarthe, N., Serrão, M.L., Melo, Y.F., de Oliveira, S.J., Lourenco-de-Oliveira, R., 1998. Potential vectors of Dirofilaria immitis (Leidy, 1856) in Itacoatiara, oceanic region of Niteroi municipality, state of Rio de Janeiro, Brazil. Mem. Inst. Oswaldo Cruz 93 (4), 425-432.

Labarthe, N., Alves, L., Serrão, M.L., 2002. Dirofilariose em pequenos animais domesticos e como zoonose. In: Almosny, N. (Ed.), Hemoparasitoses em pequenos animais domesticos e como zoonose. L.F. Livros, Rio de Janeiro, pp. 112-135.

Labarthe, N., de Campos Pereira, M., Barbarini, O., McKee, W., Coimbra, C.A., Hoskins, J., 2003. Serologic prevalence of Dirofilaria immitis, Ehrlichia canis, and Borrelia burgdorferi infections in Brazil. Vet. Ther. 4 (1), 67-75.

Labarthe, N., Paiva, J.P., Reifur, L., Mendes-de-Almeida, F., Merlo, A., Pinto, C.C., Juliani, P.S., Almeida, M.A.O., Alves, L.C., 2014. Updated canine infection rates for Dirofilaria immitis in areas of Brazil previously identified as having a high incidence of heartworm-infected dogs. Parasit. Vectors 7, 493.

Labruna, M.B., Pereira, M., 2001. Carrapato em cães no Brasil. Clin. Vet. 30, 24-32.

Little, S.E., Beall, M.J., Bowman, D.D., Chandrashekar, R., Stamaris, J., 2014. Canine infection with Dirofilaria immitis, Borrelia burgdorferi, Anaplasma spp., and Ehrlichia spp. in the United States, 2010-2012. Parasit. Vectors 7, 257.
Maia-Elkhoury, A.N., Alves, W.A., Sousa-Gomes, M.L., Sena, J.M., Luna, E.A., 2008. Visceral leishmaniasis in Brazil: trends and challenges. Cad. Saude Publica 24 (12), 2941-2947.

Newton, N.L., Wright, W.H., 1956. The occurrence of a dog filarid other than Dirofilaria immitis in the United States. J. Parasitol. 42, 246-258.

Onofrio, V.C., Barros-Battesti, D.M., Labruna, M.B., Faccini, J.L., 2009. Diagnoses of and illustrated key to the species of Ixodes Latreille, 1795 (Acari: Ixodidae) from Brazil. Syst. Parasitol. 72 (2), 143-157.

Paula, C.C., Figueiredo, F.B., Menezes, R.C., Mouta-Confort, E. Bogio, A., Madeira, M.F 2009. Canine visceral leishmaniasis in Marica, State of Rio de Janeiro: first report of an autochthonous case. Rev. Soc. Bras. Med. Trop. 42 (1), 77-78.

Santos, H.A., Pires, M.S., Vilela, J.A., Santos, T.M., Faccini, J.L.H., Baldani, C.D., Thomé, S. Sanavria, A., Massard, C.L., 2011. Detection of Anaplasma phagocytophilum in Brazilian dogs by real-time polymerase chain reaction. J. Vet. Diagn. Investig. 23 (4), 770-774.

Sykes, J.E. (Ed.), 2014 Canine and Feline Infectious Diseases, Elsevier, St Louis, Missouri.

Villeneuve, A., Goring, J., Marcotte, L., Overvelde, S., 2011. Seroprevalence of Borrelia burgdorferi, Anaplasma phagocytophilum, Ehrlichia canis, and Dirofilaria immitis among dogs in Canada. Can. Vet. J. 52 (5), 527-530.

Willi, L., Mendes-de-Almeida, F., Paiva, J.P., Marques, D.S.M., Ramos, C., Chame, M., Zaverucha, T., Labarthe, N., 2012. Dirofilaria immitis em paisagens distintas no estado do Rio de Janeiro. XVII Congresso Brasileiro de Parasitologia Veterinária. São Luis, MA Brazil.

World Health Organization (WHO), 2015. WHO health topics: Leishmaniasis. (Accessed June 2) Available at:. http://www.who.int/mediacenter/. 